\title{
LASTİK SEKTÖRÜNDE OWAS VE NASA-TLX YÖNTEMLERİ KULLANILARAK FİZİKSEL VE ZİHİNSEL İŞ YÜKÜ ÖLÇÜMÜ
}

\author{
Burcu ÖZCAN ${ }^{*}$, Enes YEĞİN2
}

${ }^{1}$ Kocaeli Üniversitesi Endüstri Mühendisliği Bölümü, ORCID No: http://orcid.org/0000-0003-0820-4238

${ }^{2}$ Kocaeli Üniversitesi Endüstri Mühendisliği Bölümü, ORCID No: http://orcid.org/0000-0001-7235-3436

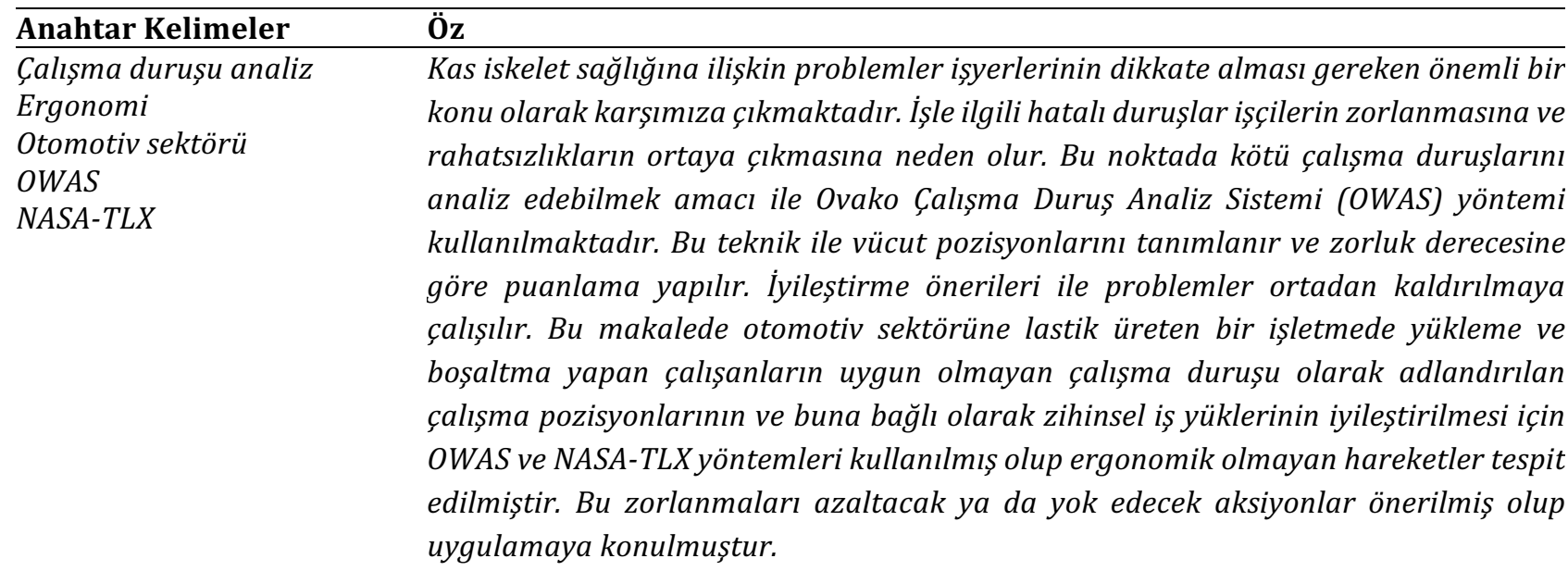

\section{PHYSICAL AND MENTAL WORK LOAD MEASUREMENT IN THE TIRE} INDUSTRY USING OWAS AND NASA-TLX METHODS

\begin{tabular}{ll}
\hline Keywords & Abstract \\
\hline Working posture analysis & Musculoskeletal health problems are an important issue that businesses should \\
Ergonomi & consider. The work related erroneous postures can cause strain and discomfort of the \\
Automotive industry & workers. At this point, Ovako Working Posture Analysing System (OWAS) method is \\
OWAS & used to analyze erroneous working postures. With this technique, body positions are \\
NASA-TLX & defined and scoring is made according to difficulty level. Improvement suggestions are \\
& tried to eliminate problemsIn this article, OWAS and NASA-TLX methods are used to \\
& improve the working positions of the employees who make loading and unloading in a \\
& company producing tires for the automotive sector, which is called the strange \\
& working posture and accordingly mental workloads and non-ergonomic movements \\
& are determined. Actions to reduce or eliminate these difficulties have been proposed \\
& and put into practice.
\end{tabular}

\begin{tabular}{llll}
\hline Araştırma Makalesi & & Research Article & \\
Başvuru Tarihi & $: 06.11 .2019$ & Submission Date & $: 06.11 .2019$ \\
Kabul Tarihi & $: 24.02 .2020$ & Accepted Date & $: 24.02 .2020$ \\
\hline
\end{tabular}

\footnotetext{
* Sorumlu yazar e-posta: burcu.ozcan@kocaeli.edu.tr
} 


\section{Giriş}

Sanayileşme ile birlikte meslek hastalıkları ve iş kazalarında artışlar başlamıştır. Risklerin ve tehlike gruplarının dikkate alınmaması firmanın güvenli çalışmasına engel olmaktadır. Bu tutum işveren ve iş̧i açısından maddi ya da manevi kayıp anlamına gelmektedir. Bu kayıpların başında kas ve iskelet sistemi yaralanmaları gelmektedir. Bu durumlar için iyileştirme adımları atılmadığı takdirde ilk aşamada ağrı şikâyeti devamında şiddetli ağrı, güçsüzlük ve hareket zorluğu ortaya çıkmaktadır. Burada esas olan bu çalışma pozisyonlarının tekrarlanması, uzun zaman boyunca uygun olmayan duruşlarda çalışıılması ve uzun süre titreşime maruz kalınması bu yaralanmaların artmasına neden olur (Ulutaş ve Gündüz, 2017).

Fiziksel risk faktörleri ise tekrarlanma, aşırı güç kullanımı, statik ve hatalı duruş gibi durumlardır. Tekrarlanma, benzer ya da aynı hareketlerin belirli bir sıklıkla gerçekleşmesi kas ve iskelet sağlık problemlerinin önce küçük çapta sonra artarak devamına neden olmaktadır. Uygun olmayan duruşlar ise iş tanımının gereği işçilerin doğal olmayan hareketleri gerekebilir, bu durumlarda kas iskelet sisteminde ani ve aşırı yüklenmeler meydana gelir. Statik duruş gerektiren durumlarda ise uzun süreler boyunca aynı pozisyonda kalma durumunda kan akışında yavaşlama başlar ve kasların kasılma şiddeti artar. Bu belirtilen durumlar ergonomik iyileştirmeler ile önlenebilir (Deste ve Sever, 2019). Çalışma alanındaki iyileştirme çalışmaları hem iş verimini arttırmakta hem de çalışanın sağlığını olumlu yönde etkilemektedir. Ergonomik düzenlemeler ile işçi zorlanmadan işini güvenle ve iş motivasyonu ile yapar hem de bu sayede şirket üretim kapasitesi hem de karlılığı açısından fayda sağlar (Sağıroğlu, vd., 2015). Literatür çalışmaları incelendiğinde ergonomik açıdan risklerin analizi için birçok yöntem vardır. Bu metotlar, çalışırken iş̧̧inin hareketlerini gözlemlemek ya da yaptığı işin öğelerini incelemek üzere tasarlanmışlardır. Ergonomik riskler değerlendirilirken işin içeriğine uygun nitelikte yöntemlerin seçilmesi önemlidir (Delice, vd., 2018). Ergonomik riskler açısından lastik ve otomotiv sektörü incelendiğince kas ve iskelet sistemi hastalıklarına iliş̧kin çeşitli çalışmalar bulunmaktadır. Rahman vd. 2009 yllında yaptığı çalışmada araç lastiği servisindeki ergonomik risk faktörleri incelenmiştir.

Anket ve yüz yüze görüşme ile vücudun farklı bölgelerinde ortaya çıkan rahatsızlıklara ilişkin tespitler yapılmıștır. Kamera ile iş süreci gözlemlenerek beş farklı görev için ergonomik tedbirler belirlenmiştir. $\mathrm{Bu}$ çalışmada; otomotiv sektörüne lastik üreten bir işletmede tırlara ve konteynerlere lastik yükleyip boşaltan çalışanların uygun olmayan duruşlarının risk analizi yapılıp bu duruşlardaki zorlanmaları azaltacak ergonomik tasarımlar ele alınmıştır. Drinkaus ve diğ. (2003) yılında yapmış oldukları çalışmada 244 otomotiv montaj firması RULA ve SI ile değerlendirilmiştir. Her bir aletin ergonomik açıdan incelenerek gamma skoru ile değerlendirilmiştir. Lavender vd. (2006) yılında yapmış olduğu çalışmada Amerika'da faaliyet gösteren yedi otomotiv dağıtım şirketinde 52 görev için iş analizi yapılmış yüksek riskli işler belirlenmiștir.

$\mathrm{Bu}$ çalışmanın amacı Malezya otomotiv endüstrilerindeki manuel malzeme taşıma işçileri arasında risk faktörleri ve kas-iskelet rahatsızlığ arasındaki ilişkiyi belirlemekti. Otomotiv endüstrilerinden toplam 211 manüel malzeme elleçleme çalışanı, bireysel, fiziksel ve çevresel faktörler ve kas-iskelet rahatsızlığının yaygınlığı hakkında bir dizi anket doldurdu. Risk faktörleri ve kas-iskelet ilişkisini belirlemek için ki-kare testi ve lojistik regresyon analizi kullanıldı (Widia ve Dawal, 2016).

Yapılan çalışma ile otomotiv sektörüne lastik üreten bir işletmede çalışma duruşları OWAS ve NASA-TLX yöntemleri kullanılmış olup riskler ve iyileştirme önerileri ortaya konmuştur.

\section{2. İş Yükü Ölçüm Yöntemleri}

Çalışma duruşlarının analizinde Hızlı tüm vücut değerlendirmesi (REBA), Hızlı üst uzuv değerlendirmesi (RULA), OWAS vb. birçok yöntem kullanılmaktadır. Bu çalışmada ilk olarak OWAS çalışma duruş analizi ve sonrasında Nasa-TLX zihinsel iş yükü ölçüm yöntemi incelenmiştir.

\subsection{OWAS (Ovako Çalışma Duruş Analiz Sistemi)}

OWAS, çalışanın kas-iskelet sisteminde yüklenmeye ve zorlanmaya neden olan hareketlerin, duruşların belirlenmesini sağlayan metottur.

OWAS yönteminde hesaplamalar duruş ve yük durumlarına göredir. Tablo 1'de görüldügüü üzere sırt duruşu, kol duruşu, bacak duruşu ve kaldırılan ağırlıklar dikkate alınarak hesaplama yapılmaktadır (Çiçek, vd., 2017). 
Tablo 1. OWAS Kodlama Yapisı

\begin{tabular}{|c|c|c|c|c|}
\hline & Sirt & Kol & Bacak & $\begin{array}{l}\text { Yük/güç } \\
\text { kullanımı }\end{array}$ \\
\hline & A & B & $\mathrm{C}$ & $\mathrm{D}$ \\
\hline 1 & Düz & $\begin{array}{l}\text { İki kol omuz } \\
\text { seviyesi altı }\end{array}$ & Oturma & $<10 \mathrm{~kg}$ \\
\hline 2 & Eğik & $\begin{array}{l}\text { Bir kol omuz } \\
\text { seviyesi üstü }\end{array}$ & $\begin{array}{c}\text { Dik konum: iki } \\
\text { bacak ayakta } \\
\text { duruş }\end{array}$ & $10-20 \mathrm{~kg}$ \\
\hline 3 & Çevrilmiş & $\begin{array}{l}\text { İki kol omuz } \\
\text { seviyesi üstü }\end{array}$ & $\begin{array}{c}\text { Dik konum: tek } \\
\text { bacak ayakta } \\
\text { duruş }\end{array}$ & $>20 \mathrm{~kg}$ \\
\hline 4 & $\begin{array}{l}\text { Bükülmüș } \\
\text { ve eğilmiş }\end{array}$ & & $\begin{array}{l}\text { Dik konum: iki } \\
\text { bacak bükülmüş } \\
\text { konumda }\end{array}$ & \\
\hline 5 & & & $\begin{array}{l}\text { Dik konum, bir } \\
\text { bacak bükülmüş } \\
\text { konumda }\end{array}$ & \\
\hline 6 & & & $\begin{array}{c}\text { Diz çökerek } \\
\text { duruş }\end{array}$ & \\
\hline 7 & & & Yürüme konumu & \\
\hline
\end{tabular}

OWAS tehlike seviyeleri Tablo 1' deki sirt, kol, bacak ve yük/güç kullanımı puanlamalarına göre yapılan hesaplamalar sonrası Tablo 2 kullanılarak belirlenmektedir.

Tablo 2. OWAS Tehlike Kategorisinin Belirlenmesi

\begin{tabular}{|c|c|c|c|c|c|c|c|c|c|c|c|c|c|c|c|c|c|c|c|}
\hline \multirow[b]{2}{*}{ Sirt } & \multirow[b]{2}{*}{ Kollar } & \multicolumn{3}{|c|}{1} & \multicolumn{2}{|c|}{2} & \multicolumn{2}{|c|}{3} & \multicolumn{3}{|c|}{4} & \multicolumn{2}{|c|}{5} & \multicolumn{3}{|c|}{6} & \multicolumn{2}{|c|}{7} & \multirow{2}{*}{\begin{tabular}{|r} 
Bacaklat \\
Kuvvet \\
Kullanim
\end{tabular}} \\
\hline & & 1 & & & & 3 & & 2 & & & 3 & & 3 & & 2 & & & 23 & \\
\hline \multirow{3}{*}{1} & 1 & 1 & 1 & 1 & 1 & 1 & 1 & 1 & 2 & 2 & 2 & 2 & 2 & 1 & 1 & & & 1 & \\
\hline & 2 & 1 & 1 & 1 & 1 & 1 & 1 & 1 & 2 & 2 & 2 & 2 & 2 & 1 & 1 & 1 & 1 & 1 & \\
\hline & 3 & 1 & 1 & 1 & 1 & 1 & 1 & $1]$ & 2 & 2 & 3 & & 3 & 1 & 1 & & 1 & 12 & \\
\hline \multirow{3}{*}{2} & 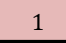 & $1-$ & & 3 & 2 & 3 & 2 & 2 & 3 & 3 & 3 & 3 & 3 & 2 & 2 & & & 33 & \\
\hline & 2 & 2 & 2 & 3 & 2 & 3 & 2 & 3 & 3 & 4 & 4 & 3 & 4 & 3 & 3 & & 2 & $\begin{array}{l}3 \\
4\end{array}$ & \\
\hline & 3 & 3 & 3 & 4 & 2 & 3 & 3 & 3 & 3 & 4 & 4 & & 4 & 4 & 4 & & 2 & \begin{tabular}{l|l}
3 & 4
\end{tabular} & \\
\hline \multirow{3}{*}{3} & 1 & 1 & & 1 & 1 & 1 & 1 & 1 & 3 & 3 & 3 & & 4 & 1 & 1 & & 1 & 1 & \\
\hline & 2 & 2 & & 3 & 1 & 1 & 1 & 1 & 4 & 4 & 4 & & 4 & 3 & 3 & 3 & 1 & 1 & \\
\hline & 3 & 12 & & 3 & & 1 & 2 & 3 & 4 & 4 & 4 & & 4 & 4 & 4 & & 1 & \begin{tabular}{l|l}
1 & 1
\end{tabular} & \\
\hline \multirow{3}{*}{4} & 1 & 12 & & 3 & 2 & 3 & 2 & 2 & 17 & 4 & 4 & & 7 & 4 & $T$ & 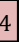 & & 34 & \\
\hline & 2 & 3 & & 4 & & & 3 & & & & 4 & & & 4 & & & & $\begin{array}{l}3 \\
4\end{array}$ & \\
\hline & 3 & 4 & & 4 & 3 & 4 & 3 & 3 & 4 & 4 & 4 & 4 & 14 & 4 & 4 & 4 & 2 & \begin{tabular}{l|l}
3 & 4
\end{tabular} & \\
\hline
\end{tabular}

Tehlike kategorisine göre şirket tarafından alınması gereken aksiyonların önem derecesi Tablo 3'te belirtilmektedir.
Tablo 3. OWAS Yöntemi Kategori Sinıflandırması

\begin{tabular}{|c|c|c|}
\hline Kategoriler & $\begin{array}{c}\text { Zorlanma / } \\
\text { Yüklenme }\end{array}$ & Düzenleme \\
\hline C1 & Normal & Gerekli değil \\
\hline C2 & az & $\begin{array}{c}\text { Yakın zamanda } \\
\text { yapılmalıdır }\end{array}$ \\
\hline C3 & orta & $\begin{array}{c}\text { Mümkün olur olmaz } \\
\text { yapılmalıdır }\end{array}$ \\
\hline C4 & çok & Acil düzenleme \\
\hline
\end{tabular}

\subsection{NASA-TLX Zihinsel İş Yükü Ölçüm Yöntemi}

NASA-TLX yöntemi tarafından üç yıl süren ve kırktan fazla laboratuarda yapılmış olan simülasyon denemeleri sonucunda ortaya çıkarılmıştır. Ergonomi alanında yapılan çalışmalar neticesinde, NASA-TLX metodu literatürde var olan diğer zihinsel iş yükü yöntemlerine göre etkin ve güvenilir olduğu ifade edilmiştir. NASA-TLX metodu Tablo 4'te gösterildiği gibi altı alt faktörü kullanarak değerlendirmektedir. Burada fiziksel aktivitelerin zihinsel iş yükünün belirlenmesi konusunda potansiyel etkisi ortaya çıkarılmaya çalıșılmaktadır (Delice, 2016).

NASA-TLX yöntemi bir çok sektörde kullanılmakta olup bu sektörler olarak Sağlık sektörü (Bayabana, vd., 2016; Yaylı ve Çalıșkan, 2019; Marano ve Nicolantonio, 2015), inşaat sektörü (Saha, vd., 2017; Kulkarni ve Devalkar, 2017; Dzeng, vd., 2018; Eom ve Lee, 2018), tarım sektörü (Kong, vd., 2018; Mishra ve Satapathy, 2019; Possebom, vd., 2018; Kong, vd., 2015) sayılabilir.

Tablo 4'te iş yükü boyutu zihinsel talep (MD), Fiziksel Talep (PD), Zamansal Talep (TD), Performans (PL), Efor/Çaba (EL), Rahatsızlık seviyesi olarak Değerlendirme ölçeği ise Düşük/Yüksek (D/Y) ve iyi/kötü (I/Y) olarak isimlendirilmiștir.

\section{Tablo 4. NASA-TLX Alt Faktör Tanımları}

\begin{tabular}{|c|c|c|}
\hline İş̧ Yükü & Ölçek & Açıklama \\
\hline MD & $\mathrm{D} / \mathrm{Y}$ & $\begin{array}{l}\text { Zihinsel olarak ne kadar algılama } \\
\text { aktivitesine ihtiyaç vardır } \\
\text { İşin hatayı kabul edebilme durumu nedir } \\
\text { İşin zorluğu ve karmaşıklığı nedir }\end{array}$ \\
\hline PD & $\mathrm{D} / \mathrm{Y}$ & $\begin{array}{l}\text { Fiziksel olarak ihtiyaç duyduğu enerjinin } \\
\text { seviyesi nedir } \\
\text { İşin yoruculuğu, hızlılığı, özel çaba } \\
\text { gerektirmesi ne boyuttadır. }\end{array}$ \\
\hline TD & $\mathrm{D} / \mathrm{Y}$ & $\begin{array}{l}\text { Zaman kısıtlığının iş üzerindeki etkisi nedir } \\
\text { İşi gerçekleştirmek için gerekli olan } \\
\text { adımların hızlı olması ne kadar zorunludur. }\end{array}$ \\
\hline
\end{tabular}




\begin{tabular}{ccl}
\hline PL & İK & $\begin{array}{l}\text { İş hedeflerine başarı noktasında ne } \\
\text { seviyedeyiz } \\
\text { İş̧ tatmini olarak ne konumdayız }\end{array}$ \\
\hline EL & D/Y & $\begin{array}{l}\text { Zihinsel ve fiziksel olarak çalışma } \\
\text { koşullarının ağırlığı nedir }\end{array}$ \\
\hline FL & D/Y & $\begin{array}{l}\text { İş konusundaki memnuniyetsizlik } \\
\text { güvensizlik ve gerilmişlik seviyesi nedir. }\end{array}$ \\
\hline
\end{tabular}

\section{Yöntem OWAS Ve NASA-TLX Yöntemleri Kullanılarak Lastik Sektöründen Bir Uygulama}

Çalışma uzun yıllar Lastik Sektöründe faaliyet gösteren bir firmada gerçekleşmiştir. Lastiklerin yüklenme ve boşaltılma esnasında çalışanın duruşunda uygunsuzlukların mevcut olduğu saptanmıştır. Ambar çalışanları insan kapasitesinin üstünde bir ağırlık kaldırmaya maruz kalmaktadır. Lastik yükleme/boşaltma işlemi bir vardiyada çok sık tekrarlanmaktadır. OWAS yöntemi ile lastik yüklemesi/boşaltımı yapılırken duruş ve çalışma hareketlerinin risk dereceleri belirlenmiștir. Yüklemeler yanları açık bir ortamda yapıldığı için ortam özellikle kış aylarında çalışmaya elverişsli değildir. Ağır kamyon lastiklerini (60-120 kg) göz önünde bulundurarak iş kazası riski bulunmaktadır.

Uygulama için çalışanların 3 duruşu analiz edilir.

Ilk duruş Şekil 1 de gösterilen lastiğin araçtan boşaltımı için çalışanın ayakta durduğu, her iki kolunu kaldırıp lastiği aldığı ve yana döndüğü harekettir.

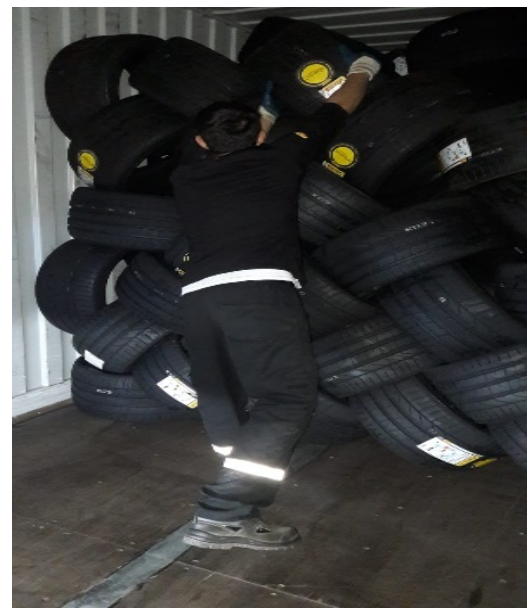

\section{Şekil 1. Lastiklerin Araçtan Boşaltılması}

Şekil 1'de gösterilen fotoğrafta ișçi istif olarak yüklenmiş lastikleri kaldırmaktadır. Bu hareket tablo 5'te analiz edilmiştir. Tabloda sırt, kollar ve bacaklar olmak üzere üç bölge incelenmiștir. Duruşlar ve kod numarası tablo 1'den yararlanarak aşağıdaki gibi belirtilmiştir.
Tablo 5. İlk Duruş İçin Kod Ve Tehlike Seviyeleri

\begin{tabular}{|c|c|c|}
$\begin{array}{c}\text { Incelenen } \\
\text { bölge }\end{array}$ & Kod & Duruşlar \\
\hline Sırt & 3 & Bükülmüş \\
\hline Kollar & 3 & $\begin{array}{c}\text { Her iki kol omuz } \\
\text { hizasının üstünde }\end{array}$ \\
\hline Bacaklar & 3 & $\begin{array}{c}\text { Dik olarak tek bacak } \\
\text { üstünde ayakta durma }\end{array}$ \\
\hline Yük & 3 & 20 kg üstünde \\
\hline $\begin{array}{c}\text { Tehlike } \\
\text { seviyesi }\end{array}$ & $3-3-3-3$ & \\
\hline C3 & $\begin{array}{c}\text { Kategori } \\
\mathbf{3}\end{array}$ & $\begin{array}{c}\text { Orta derecede zorlanma } \\
\text { mevcuttur. Mümkün olur } \\
\text { olmaz ergonomik } \\
\text { düzenleme yapıllmalıdır. }\end{array}$ \\
\hline
\end{tabular}

İkinci duruş ise; çalışanın eğilip büküldüğü ve lastiği bankellere koyan kişiye doğru lastiği yuvarlama hareketi yapacak şekilde firlatmasıdır. Bu hareket Şekil 2. de gösterilmiştir.

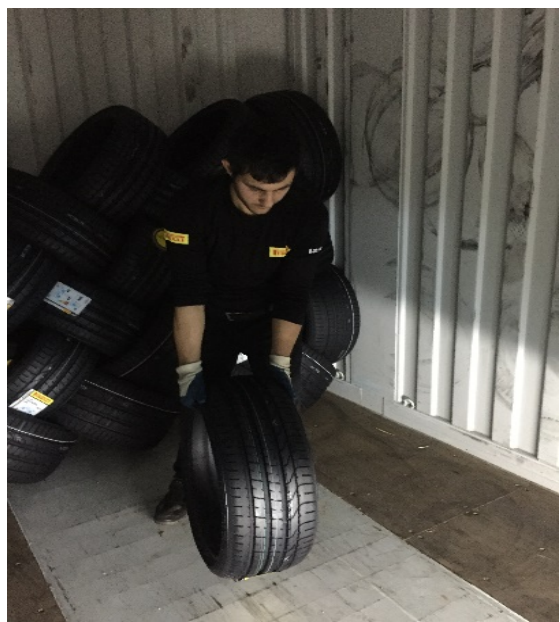

Şekil 2. İstiften Alınan Lastiğin Fırlatılması

Şekil 2'de gösterilen fotoğraf için tablo 6'da sırt, kollar ve bacaklar olmak üzere üç bölge incelenmiștir.

Tablo 6. İkinci Duruş Kod Ve Tehlike Seviyeleri

\begin{tabular}{|c|c|c|}
\hline $\begin{array}{c}\text { Incelenen } \\
\text { bölge }\end{array}$ & Kod & Duruşlar \\
\hline Sırt & 4 & Eğilmiş \& Bükülmüş \\
\hline Kollar & 1 & Her iki kol omuz hizasının altında \\
\hline Bacaklar & 3 & $\begin{array}{c}\text { Dik olarak tek bacak üstünde ayakta } \\
\text { durma }\end{array}$ \\
\hline Yük & 3 & 20 kg üstünde \\
\hline $\begin{array}{c}\text { Tehlike } \\
\text { seviyesi }\end{array}$ & $4-1-3-3$ & \\
\hline
\end{tabular}




\begin{tabular}{|c|c|c|}
\hline C3 & Kategori & Orta seviyede zorlanma mevcuttur. \\
& $\mathbf{3}$ & Mümkün olur olmaz ergonomik \\
düzenleme yapılmalıdır.
\end{tabular}

Üçüncü duruş ise; çalışanın eğildiği büküldüğü ve lastiği yerden alıp bankellere koyma hareketidir. $\mathrm{Bu}$ hareket Şekil 3'te gösterilmiştir.

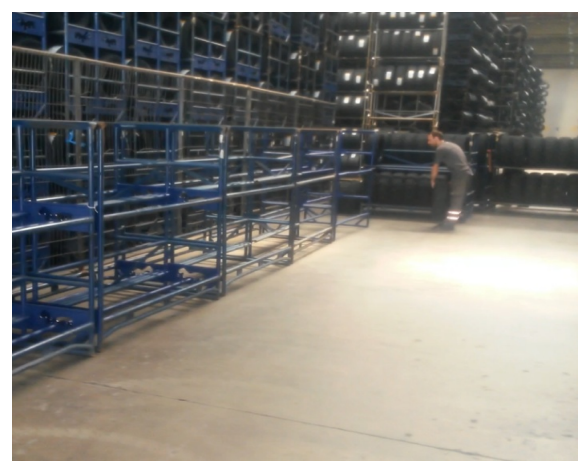

Şekil 3. Lastiklerin Bankellere Konulması

Şekil 4'de gösterilen fotoğraf için tablo 7'de sırt, kollar ve bacaklar olmak üzere üç bölge incelenmiştir. Duruşlar ve kod numarası Tablo 1'den yararlanarak aşağıdaki gibi belirtilmiştir.

Tablo 7. Üçüncü Duruş Kod Ve Tehlike Seviyeleri

\begin{tabular}{|c|c|c|}
\hline $\begin{array}{l}\text { İncelenen } \\
\text { bölge }\end{array}$ & Kod & Duruşlar \\
\hline Sirt & 2 & Eğilmiş \\
\hline Kollar & 1 & Her iki kol omuz hizasının altında \\
\hline Bacaklar & 2 & $\begin{array}{l}\text { Dik olarak iki bacak üstünde ayakta } \\
\text { durma }\end{array}$ \\
\hline Yük & 3 & $20 \mathrm{~kg}$ üstünde \\
\hline $\begin{array}{l}\text { Tehlike } \\
\text { seviyesi }\end{array}$ & $2-1-2-3$ & \\
\hline C3 & $\begin{array}{c}\text { Kategori } \\
\mathbf{3}\end{array}$ & $\begin{array}{l}\text { Orta seviyede zorlanma mevcuttur. } \\
\text { Mümkün olur olmaz ergonomik } \\
\text { düzenleme yapılmalıdır. }\end{array}$ \\
\hline
\end{tabular}

Tablo 5, 6 ve 7 incelendiğinde özellikle çalışanların ergonomik olmayan çalışma şartlarına sahip olduğu görülmektedir. $\mathrm{Bu}$ şekilde çalışmaya devam edilmemesi ve mümkün olan en kısa zamanda düzenlemelerin yapılması gerekmektedir.

İşçilerin fiziksel iş yüklerine ek olarak zihinsel iş yükleri de incelenmiştir. Tablo 8'de iş yükü değerleri görülmektedir. İş gereksinim faktörleri zihinsel talep, fiziksel talep, zamansal talep, performans, çaba/efor ve rahatsızlık seviyesi 10 farklı işçi tarafından 100 'lük puan sistemine göre puanlanarak incelenmiştir. Sıfıra yakın değerler düşük zorlanma derecesini, 100'e değerler yüksek zorlanma derecesini göstermektedir. Değerlendirmelere göre çıkan sonuçlar Tablo 8'deki gibidir.

Tablo 8. İş Yükü Değerleri

\begin{tabular}{|l|c|c|c|c|c|c|c|c|c|c|c|}
\hline \multirow{2}{*}{ Faktör } & \multicolumn{10}{|c|}{ İçiler } & Ort \\
\cline { 2 - 13 } & 1 & 2 & 3 & 4 & 5 & 6 & 7 & 8 & 9 & 10 & \\
\hline Zihinsel & 60 & 35 & 25 & 55 & 45 & 35 & 40 & 45 & 30 & 50 & 42 \\
\hline Fiziksel & 95 & 80 & 80 & 95 & 75 & 80 & 70 & 85 & 90 & 80 & 83 \\
\hline Zamansal & 85 & 85 & 90 & 100 & 95 & 95 & 95 & 90 & 85 & 90 & 91 \\
\hline Performans & 80 & 80 & 70 & 90 & 90 & 75 & 80 & 70 & 85 & 60 & 78 \\
\hline Çaba/Efor & 65 & 85 & 85 & 90 & 60 & 60 & 80 & 70 & 55 & 80 & 73 \\
\hline $\begin{array}{l}\text { Rahatsızlık } \\
\text { Seviyesi }\end{array}$ & 40 & 30 & 35 & 90 & 50 & 50 & 70 & 20 & 40 & 35 & 46 \\
\hline
\end{tabular}

İş yükü değerleri incelendiğinde işçilerin özellikle Fiziksel ve Zamansal olarak ciddi zorlanmalara sahip olduğu gözlemlenmektedir. Günlük araç yükleme hedefinin 21 adet olması çalışanları zamanla yarış halinde çalışmaya zorlamaktadır. Bu faktörün etkisi

Tablo 8'de çalışanların özellikle zamansal ve fiziksel iş yükü puanlamalarına olumsuz yansımış olarak karşımıza çıkmaktadır.

Tablo 9'da örneklemelerin ortalama puanları referans alınarak her iş gereksinim faktörü için ortalama değeri yüksek olan faktör işaretlenmiştir.

Tablo 9. NASA-TLX Ağırlıklandırma Ölçeği

\begin{tabular}{|c|c|c|c|c|c|}
\hline \multirow{2}{*}{ 1) } & & Zihinsel & \multirow{2}{*}{ 8) } & Fiziksel & $\mathrm{X}$ \\
\hline & $\mathbf{X}$ & Fiziksel & & Çaba/Efor & \\
\hline \multirow[b]{2}{*}{ 2) } & & Zihinsel & \multirow[b]{2}{*}{ 9) } & Fiziksel & $\mathrm{X}$ \\
\hline & $\mathbf{X}$ & Zamansal & & $\begin{array}{c}\text { Rahatsızlık } \\
\text { Seviyesi }\end{array}$ & \\
\hline \multirow{2}{*}{ 3) } & & Zihinsel & \multirow{2}{*}{ 10) } & Zamansal & $\mathrm{X}$ \\
\hline & $\mathbf{X}$ & Performans & & Performans & \\
\hline \multirow{2}{*}{ 4) } & & Zihinsel & \multirow{2}{*}{ 11) } & Zamansal & $\mathrm{X}$ \\
\hline & $\mathbf{X}$ & Çaba/Efor & & Çaba/Efor & \\
\hline \multirow[b]{2}{*}{ 5) } & & Zihinsel & \multirow[b]{2}{*}{ 12) } & Zamansal & $\mathrm{X}$ \\
\hline & $\mathbf{X}$ & $\begin{array}{c}\text { Rahatsızlık } \\
\text { Seviyesi }\end{array}$ & & $\begin{array}{c}\text { Rahatsızlık } \\
\text { Seviyesi }\end{array}$ & \\
\hline \multirow{2}{*}{ 6) } & & Fiziksel & \multirow{2}{*}{ 13) } & Performans & $\mathrm{X}$ \\
\hline & $\mathbf{X}$ & Zamansal & & Çaba/Efor & \\
\hline \multirow{4}{*}{ 7) } & $\mathbf{X}$ & Fiziksel & \multirow[b]{2}{*}{ 14) } & Performans & $\mathrm{X}$ \\
\hline & & Performans & & $\begin{array}{c}\text { Rahatsızlık } \\
\text { Seviyesi }\end{array}$ & \\
\hline & & & \multirow[b]{2}{*}{ 15) } & Çaba/Efor & $\mathrm{X}$ \\
\hline & & & & $\begin{array}{c}\text { Rahatsızlık } \\
\text { Seviyesi }\end{array}$ & \\
\hline
\end{tabular}


$\mathrm{TLX}=\mathrm{MD} \times \mathrm{W}_{\mathrm{MD}}+\mathrm{PD} \times \mathrm{W}_{\mathrm{PD}}+\mathrm{TD} \times \mathrm{W}_{\mathrm{TD}}+\mathrm{FL} \times \mathrm{W}_{\mathrm{FL}}+\mathrm{EL}$ $x W_{E L}+P L x W_{P L}$

Burada, $\mathrm{W}_{\mathrm{xx}}$, her bir iş yükü alt faktörünün ağırlığını göstermektedir. Bu değeri belirlerken Tablo 7'de ilgili iş gereksinim faktörünün ortalama değerinin kaç farklı faktöre göre yüksek olduğu dikkate alınmıştır. Örnek olarak Fiziksel iş faktörü Tablo 7'de Zihinsel, Performans, Çaba/Efor ve Rahatsılılk seviyesi olmak üzere 4 farklı iș faktörüne göre daha yüksek puanlamaya sahiptir. MD, PD, TD, FL, EL ve PL oranlama aşamasında altı faktörün her biri için Tablo 8'da belirlenen oranlama değerleridir.

$T L X=\frac{42 \times 0+83 \times 4+91 \times 5+78 \times 3+73 \times 2+46 \times 1}{15}=80,87$

Zihinsel iş yükü değeri 80,87 çıkmıștır. 100'lük puan sistemi referans alındığında bu değer çalışanların yüksek derecede zihinsel iş yüküne maruz kaldığını göstermektedir. 50-60 bandına çekilmesi için özellikle zamansal ve fiziksel talep noktalarında düzenleme yapılması gerekmektedir.

\section{1. İyileştirme Önerileri}

Fiziksel ve zihinsel iş yükleri OWAS ve NASA-TLX yöntemleri uygulanarak ölçülmüştür. $\mathrm{Bu}$ ölçümlerden de görüldüğü üzere işçiler hem fiziksel hem de zihinsel iş yüküne maruz kalmaktadır. Bu iş yüklerini azaltmak için aşağıdaki öneriler geliştirilmiştir.

- Alçalıp yükselebilen konveyör bandı yapılması

- Özellikle kamyon lastikleri ağır olduğu için yükleme/boşaltma için 2 kişinin aynı anda kaldırma indirme hareketi yapması

- Şekillerden görüleceği üzere çalışanlar ergonomik çalışma yöntemi hakkında eğitim alması ve yükleme hareketlerinde ergonomik kurallara dikkat edilmesinin sağlanması

- Ortam soğuk olduğu için ortama ısıtıcı bir kaynak konulması ve açı alanların kapatılması

- Günlük sevkiyat sayısının araç bazında azaltılması önerilir.

İyileştirmeler Sonrası OWAS ve NASA-TLX yöntemlerinin tekrar incelenmiştir. Yapılan öneri ve alınan aksiyonlar sonucu ambar çalışma ortamının son hali aşağıda Şekil 4 ve 5 'de belirtildiği gibidir.

Şekil 4'te iyileştirme sonrası konveyör bandı yapılması ile işçinin hafif eğilme hareketi ile lastiği konveyöre doğru iterek birakma hareketi gözlemlenmektedir. Burada konveyör ile lastik arasındaki sürtünme etkisiyle lastik konveyör bandı üzerine çlkabilmektedir.

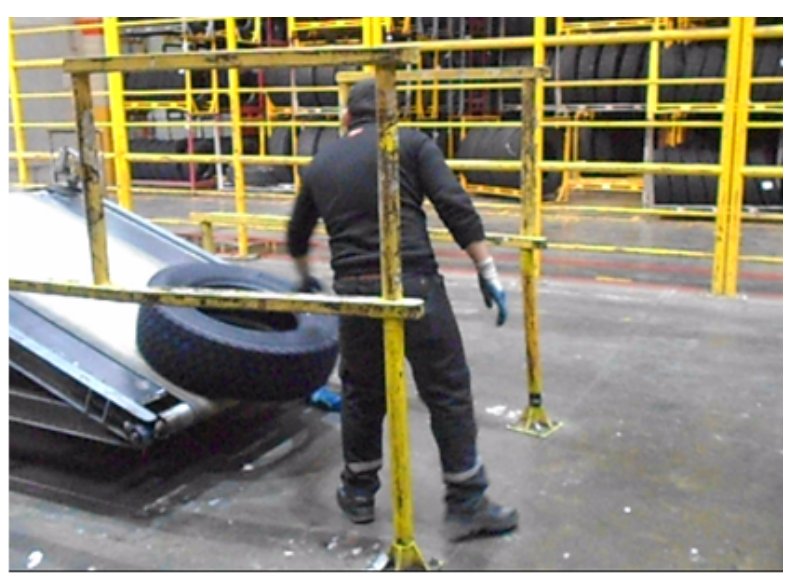

Şekil 4. Lastiğin Konveyör Bandına Bırakılması

Konveyör bandı işçinin lastiği fırlatma ve fazla eğilme gereksinimini ortadan kaldırmıştır. İşçinin fiziksel zorlanmasındaki azalma duruş kodlarıyla Tablo 10'da net bir şekilde gözlenebilmektedir.

Tablo 10. Şekil 4 İçin Kodlar Ve Tehlike Seviyeleri

\begin{tabular}{|c|c|c|}
\hline $\begin{array}{l}\text { İncelenen } \\
\text { bölge }\end{array}$ & Kod & Duruşlar \\
\hline Sirt & 2 & Eğilmiş \\
\hline Kollar & 1 & $\begin{array}{l}\text { Her iki kol omuz hizasının } \\
\text { altında }\end{array}$ \\
\hline Bacaklar & 2 & $\begin{array}{c}\text { Dik olarak iki bacak üstünde } \\
\text { ayakta durma }\end{array}$ \\
\hline Yük & 1 & $10 \mathrm{~kg}$ altında \\
\hline $\begin{array}{l}\text { Tehlike } \\
\text { seviyesi }\end{array}$ & $2-1-2-1$ & \\
\hline C2 & $\begin{array}{c}\text { Kategori } \\
2\end{array}$ & $\begin{array}{c}\text { Az seviyede zorlanma mevcuttur. } \\
\text { Yakın zamanda ergonomik } \\
\text { düzenleme yapılmalıdır. }\end{array}$ \\
\hline
\end{tabular}

Şekil 5'te işçilerin lastikleri konveyör bandından alıp araç içine koyma hareketi gerçekleşmektedir.

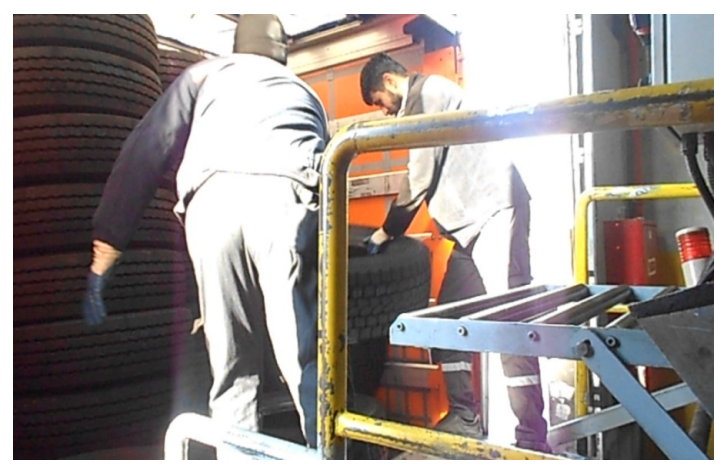

Şekil 5. Lastiklerin Araç İçine Konulması 
Çalışan sayısının arttırılması ile kişi başına düşen yük azaltılmıştır. Buna ek olarak alçalıp yükselebilen konveyör bandı ile yüksekten ya da alçaktan lastik alma gereksinimi ortadan kaldırılmıştır. İş yükü değişimindeki azalma Tablo 11'da belirtilen duruş kodlarıyla da gözlemlenmektedir.

Tablo 11. Şekil 5 İçin Kod Ve Tehlike Seviyeleri

\begin{tabular}{|c|c|c|}
\hline $\begin{array}{l}\text { İncelenen } \\
\text { bölge }\end{array}$ & Kod & Duruşlar \\
\hline Sirt & 4 & Eğilmiş \& Bükülmüş \\
\hline Kollar & 1 & Her iki kol omuz hizasının altında \\
\hline Bacaklar & 2 & $\begin{array}{l}\text { Dik olarak iki bacak üstünde ayakta } \\
\text { durma }\end{array}$ \\
\hline Yük & 1 & $10 \mathrm{~kg}$ altında \\
\hline $\begin{array}{l}\text { Tehlike } \\
\text { Seviyesi }\end{array}$ & $4-1-2-1$ & \\
\hline C2 & $\begin{array}{c}\text { Kategori } \\
2\end{array}$ & $\begin{array}{c}\text { Az seviyede zorlanma mevcuttur. Yakın } \\
\text { zamanda ergonomik düzenleme } \\
\text { yapılmalıdır. } \\
\end{array}$ \\
\hline
\end{tabular}

Zihinsel iş yükünün NASA-TLX ile tekrar incelenmiştir. Alınan aksiyonlar sonrası aynı ișçiler iş gereksinim faktörlerini puanlamıştır. Alınan 10 örneklem Tablo 12'de gösterildiği gibidir.

Tablo 12. İș Yükü Değerleri

\begin{tabular}{|c|c|c|c|c|c|c|c|c|c|c|c|}
\hline \multirow{2}{*}{ Faktör } & \multicolumn{10}{|c|}{ Ișciler } & \multicolumn{10}{c|}{ Ort } \\
\cline { 2 - 12 } & 1 & 2 & 3 & 4 & 5 & 6 & 7 & 8 & 9 & 10 & \\
\hline Zihinsel & 45 & 25 & 20 & 30 & 20 & 30 & 5 & 35 & 30 & 15 & $\begin{array}{c}25 \\
5\end{array}$ \\
\hline Fiziksel & 75 & 55 & 40 & 80 & 75 & 50 & 45 & 55 & 75 & 60 & 61 \\
\hline Zamansal & 50 & 45 & 60 & 30 & 30 & 55 & 50 & 35 & 50 & 25 & 43 \\
\hline Performans & 90 & 85 & 95 & 90 & 90 & 80 & 100 & 80 & 85 & 100 & $\begin{array}{c}89 \\
5\end{array}$ \\
\hline Çaba/Efor & 50 & 45 & 60 & 70 & 40 & 35 & 20 & 35 & 50 & 30 & $\begin{array}{c}43 \\
5\end{array}$ \\
\hline $\begin{array}{c}\text { Rahatsızlık } \\
\text { Seviyesi }\end{array}$ & 30 & 30 & 35 & 60 & 15 & 40 & 10 & 20 & 40 & 20 & 30 \\
\hline
\end{tabular}

Tablo 13'te yeni alınan örneklemelerin ortalama puanları referans alınarak her iş gereksinim faktörü için ortalama değeri yüksek olan faktör işaretlenmiştir.

Tablo 13. NASA-TLX Ağırlıklandırma Ölçeği

\begin{tabular}{|c|c|c|c|c|c|}
\hline \multirow{2}{*}{ 1) } & & Zihinsel Talep & \multirow{2}{*}{ 8) } & Fiziksel Talep & $\mathrm{X}$ \\
\hline & $\mathbf{X}$ & Fiziksel Talep & & Çaba/Efor & \\
\hline \multirow[b]{2}{*}{ 2) } & & Zihinsel Talep & \multirow[b]{2}{*}{ 9) } & Fiziksel Talep & $\mathrm{X}$ \\
\hline & $\mathbf{X}$ & Zamansal Talep & & $\begin{array}{l}\text { Rahatsızlık } \\
\text { Seviyesi }\end{array}$ & \\
\hline \multirow{2}{*}{ 3) } & & Zihinsel Talep & \multirow{2}{*}{ 10) } & Zamansal Talep & \\
\hline & $\mathbf{X}$ & Performans & & Performans & $\mathrm{X}$ \\
\hline 4) & & Zihinsel Talep & 11) & Zamansal Talep & \\
\hline
\end{tabular}

\begin{tabular}{|c|c|c|c|c|c|}
\hline & $\bar{X}$ & Çaba/Efor & & Çaba/Efor & $\bar{X}$ \\
\hline \multirow[b]{2}{*}{ 5) } & & Zihinsel Talep & \multirow[b]{2}{*}{ 12) } & Zamansal Talep & $\mathrm{X}$ \\
\hline & $\mathbf{X}$ & $\begin{array}{l}\text { Rahatsızlık } \\
\text { Seviyesi }\end{array}$ & & $\begin{array}{l}\text { Rahatsızlık } \\
\text { Seviyesi }\end{array}$ & \\
\hline \multirow{2}{*}{ 6) } & $\mathbf{X}$ & Fiziksel Talep & \multirow{2}{*}{ 13) } & Performans & $\mathrm{X}$ \\
\hline & & Zamansal Talep & & Çaba/Efor & \\
\hline \multirow[b]{2}{*}{ 7) } & & Fiziksel Talep & \multirow[b]{2}{*}{ 14) } & Performans & $\mathrm{X}$ \\
\hline & $\mathbf{X}$ & Performans & & $\begin{array}{l}\text { Rahatsızlık } \\
\text { Seviyesi }\end{array}$ & \\
\hline & & & \multirow[b]{2}{*}{ 15) } & Çaba/Efor & $\mathrm{X}$ \\
\hline & & & & $\begin{array}{l}\text { Rahatsızlık } \\
\text { Seviyesi }\end{array}$ & \\
\hline
\end{tabular}

$T L X=$ MD $\times$ WMD + PD $\times$ WPD + TD $\times$ WTD + FL $x W F L+E L x W E L+$ PL xWPL

$$
T L X=\frac{25,5 \times 0+61 \times 4+43 \times 2+89,5 \times 5+43,5 \times 3+30 \times 1}{15}=62,53
$$

\section{Sonuçlar}

İşletmeler ve çalışanlar açısından çalışma duruşlarının incelenmesi ve çözüm bulunması ergonomi bilimi içerisinde önemli bir yer tutmaktadır (Akay, 2003). Ülkemizde kauçuk ve plastik sektörü ise iş kazaları açısından bakıldığında 13. sırada; Lastik sektörü de "çok tehlikeli" olarak sinıflandırılmaktadır (Özkahraman, 2016). Bu çalışmada lastik sektöründe faaliyet gösteren bir işletmede yapılmıştır. Üretim sahasında yapılan OWAS ve NASA-TLX analizlerinde ergonomik çalışma şartlarının olmadığı tespit edilmiştir. $\mathrm{Bu}$ olumsuz çalışma durumuna devam edilmesi halinde bir süre sonra çalışanların sağlık problemlerinin oluşmasına sebep olacağı aşikârdır. Bu nedenle öneriler geliștirilmiş ve ergonomik çalışma şartlarının oluşturulması için gerekli aksiyonlar alınmıştır. Konveyör bandı önerisi her ne kadar yüksek yatırım gerektirse de işçilerin yıpranmasını, sağlık faktörlerini ve zaman kavramını göz önüne aldığımızda uzun sürede geri dönüşü olumlu olan bir yatırımdır. Bandın yükselebilir alçalabilir özelliğiyle omuz hizasının üstünden ya da aşağısından lastik alımına son verilerek eğilme kalkma hareketleri minimuma indirgenmiştir. Lastik taşıma, yuvarlama işlemlerine son verilerek yuvarlanırken yere düşen lastikleri alıp kaldırma gibi bir durum kalmamıştır. Otomatik etiketleme makinesi alınması sonrası manüel etiketleme yapan kişiler yükleme ekiplerine dahil edilerek mevcut kadro verimli bir şekilde kullanılmaya çalışılmıştır. Böylece bir aracı yükleyen kişi sayısı 2'den 3'e çıkarılmıştır. Bu sayede kişi başına düşen ağırlık/iş yükünde azalma gerçekleşmiştir. Ortama ısıtıcı eklenmiş ve açık olan araç rampa yanları kapatılmıştır. Alınan tüm aksiyonlar ve iş yükü değerlendirmeleri incelendiğinde ergonomik açıdan büyük bir gelişim olduğunu açıklıkla belirtilebilir. Özellikle konveyör bandı yatırımı ile işçiler hem fiziksel hem zamansal talepleri daha kolay karşılama olanağı bulmuştur. Bu 
sayede araç yükleme ve boșaltma hızları da artmıștır. Ek olarak günlük 21 adetlik araç yükleme hedefi 16 adet araca indirilerek işçiler üzerindeki zaman baskısı azaltılmıştır.

Tüm bu aksiyonların sonucunda daha ergonomik iş şartları sağlanmış olsa da çalışanların zorlanmaları kategori 2 seviyesinde devam etmektedir. Ergonomik açıdan çalışma şartlarının tamamen sağlanabilmesi için yüklemelerin otomatik ya da uzaktan kumandalı bir robotik kol ile yapılması gerekmektedir. Bu aksiyonun uzun vadeli yatırım planları içerisinde yer alması için şirkete öneride bulunulmuştur.

\section{Çıkar Çatışması}

Yazarlar tarafından herhangi bir çıkar çatışması beyan edilmemiștir.

\section{Kaynaklar}

Akay D. Kurt M. ve Dağdeviren, M. (2003). Çalışma Duruşlarının Ergonomik Analizi. Gazi Üniversitesi Mühendislik-Mimarlık Fakültesi Dergisi, 18(3),7384.

Bayabana, S. J., Mendozaa, K. I., Pentecostesa, M., \& Tangsoca, J. (2016). An Ergonomic Assessment of A Philippine Hospital Patient Room. In Proceedings of the DLSU Research Congress, Manila, Philippines.

Çiçek, E., Kazanç, N., ve Kahya, E. (2017). Bir Mobilya İşletmesinin Montaj Hattında Ergonomik Risk Analizi. Mühendislik Bilimleri ve Tasarım Dergisi, 6, 67-82.

Delice, E. K. (2016). Acil Servis Hekimlerinin NasaRtlx Yöntemi İle Zihinsel İș Yüklerinin Değerlendirilmesi: Bir Uygulama Çalışması. Atatürk Üniversitesi Íktisadi ve İdari Bilimler Dergisi, 30(3), 645-652.

Delice, E. K., İlknur, A. Y. I. K., Abidinoğlu, Ö. N., Çiftçi, N. N., ve Sezer, Y. (2018). Ergonomik Risk Değerlendirme Yöntemleri Ve AHP Yöntemi İle Çalışma duruşlarının Analizi: Ağır ve Tehlikeli İşler İçin Bir Uygulama. Mühendislik Bilimleri ve Tasarım Dergisi, 6, 112-124.

Deste, M., ve Sever, S. (2019). İmalat İşletmelerinde Ergonomik Risk Değerlendirme Yöntemleri Üzerine Bibliyometrik Bir Analiz. Ekev Akademi Dergisi, ICOAEF Özel Sayısı, 209-224.
Drinkaus, P., Sesek, R., Bloswick, D., Bernard, T., Walton, B., Joseph, B., \& Counts, J. H. (2003). Comparison of Ergonomic Risk Assessment Outputs from Rapid Upper Limb Assessment and the Strain Index for tasks in automotive assembly plants. Work, 21(2), 165-172.

Dzeng, R. J., Chiang, Y. P., Watanabe, K., \& Hsueh, H. H. (2018). Marker less Based Detection of Repetitive Awkward Postures for Construction Workers. International Academic Research Conference, s. 75, Vienna.

Eom, R. I., \& Lee, Y. (2018). Analysis of Working Posture for Construction Workers Using OWAS Method. Fashion \& Textile Research Journal, 20(6), 704-712.

Kong, Y. K., Lee, S. J., Lee, K. S., Kim, G. R., \& Kim, D. M. (2015). Development of An Ergonomics Checklist for Investigation of Work-Related Whole-Body Disorders in Farming-AWBA: Agricultural Whole-Body Assessment. Journal of Agricultural Safety and Health, 21(4), 207-215.

Kong, Y. K., Lee, S. Y., Lee, K. S., \& Kim, D. M. (2018). Comparisons of Ergonomic Evaluation Tools (ALLA, RULA, REBA and OWAS) for Farm Work. International Journal of Occupational Safety and Ergonomics, 24(2), 218-223.

Kulkarni, V. S., \& Devalkar, R. V. (2017). Ergonomic Analysis of Postures of Building Construction Workers Using RII \& PATH Method. International Journal of Innovative Research in Science, Engineering and Technology, 6(1),1053-1060.

Lavender, S. A., Oleske, D. M., Andersson, G. B., \& Kwasny, M. M. (2006). Low-back Disorder Risk in Automotive Parts Distribution. International Journal of Industrial Ergonomics, 36(9), 755-760.

Marano, A., \& Di Nicolantonio, M. (2015). Ergonomic Design in eHealthcare: A Study Case of eHealth Technology System. Procedia Manufacturing, 3, 272-279.

Mishra, D., \& Satapathy, S. (2019). An Integrated MCDM and Ergonomic Approach for Agricultural Sectors of Odisha in India: A Critical Analysis for Farming Sustainability. In Advanced Multi- 
Criteria Decision Making for Addressing Complex Sustainability Issues IGI Global, 181-221.

Özkahraman, B. C. (2016). Lastik Sektöründe Faaliyet Gösteren İșletmelerde İSG Risklerinin Tespiti ve Çözüm Önerileri, İş Sağlığı ve Güvenliği Uzmanlık Tezi, Çalışma ve Sosyal Güvenlik Bakanlığı İş Sağliğı ve Güvenliği Genel Müdürlüğü, Ankara.

Possebom, G., Santos Alonço, A. S., Bellochio, S. D. C., Lopes, T. G., Carpes, D. P., Becker, R. S., \& Ruiz Zart, B. C. C. (2018). Comparison of Methods for Postural Assessment in The Operation of Agricultural Machinery. J Agric Sci. https://doi. org/10.5539/jas. v10n9p252.

Rahman, A., Nasrull, M., Abdul Aziz, F., \& Mohd Yusuff, R. (2009). Investigation of Ergonomic Risk Factors in A Car Tyre Service Centre, National Symposium on Advancements in Ergonomics and Safety, s.137, Perlis, Malaysia.

Sağıroğlu, H., Coşkun, M. B., ve Erginel, N. (2015). Reba İle Bir Üretim Hattındaki İş İstasyonlarının Ergonomik Risk Analizi. Mühendislik Bilimleri ve Tasarım Dergisi, 3(3), 339-345.

Saha, P., Basu, B., \& D. Sen, D. (2017). Ergonomic Evaluation of Physiological Stress of Building Construction Workers Associated With Manual Material Handling Tasks. Progress in Health Sciences, 7(1), 54-62.

Ulutaş, İ. B. ve Gündüz, T. (2017). Otomotiv Kablo İmalatında Ergonomik Risk Analizi. Uludağ University Journal of The Faculty of Engineering 22(2), 107-120.

Widia, M., \& Dawal, S. Z. M. (2016). The Relation of Risk Factors and Musculoskeletal Discomfort Among Manual Material Handling Workers in Malaysian Automotive Industries. Malaysian Journal of Public Health Medicine, (1), 124-133.

Yaylı, D., \& Çalışkan, E. (2019). Comparison of Ergonomic Risk Analysis Methods for Working Postures of Forest Nursery Workers. European Journal of Forest Engineering, 5(1), 18-24. 